\title{
Benzoat esteri içeren kumarin yapılı bileşiğin deneysel ve kuantum kimyasal hesaplamarı
}

\author{
Kamuran SARAÇ ${ }^{1 *}$, Serap ÇETINKAYA ${ }^{2}$ \\ ${ }^{1}$ Bitlis Eren Üniversitesi, Fen Edebiyat Fakültesi Kimya Bölümü, Bitlis \\ ${ }^{2}$ Sivas Cumhuriyet Üniversitesi, Fen Fakültesi, Moleküler Biyoloji ve Genetik Bölümü, Sivas \\ (ORCID: 0000-0001-6684-8969) (ORCID: 0000-0001-7372-1704)
}

\begin{abstract}
$\ddot{O} \mathbf{z}$
Çalışmanın amacı 4-Kumarinil-4-florobenzoatı sentezleyerek deneysel ve teorik özelliklerini tespit etmekti. 4Kumarinil-4-florobenzoat, aroil bileşiklerinin nükleofilik katılma-ayırma reaksiyonu kullanılarak sentezlendi. Bu bağlamda 4-kumarinil 4-florobenzoat bileşiği, kuantum kimyasal hesaplamalar ve spektral teknikler kullanılarak hem deneysel hem de teorik olarak karakterize edilmiştir. Bileşiğin temel halde ${ }^{1} \mathrm{H}$ ve ${ }^{13} \mathrm{C}$ 'ün nükleer manyetik rezonansları ve infrared spektroskopik değerleri hem deneysel olarak hem de teorik olarak hesaplandı (teorik hesaplamalar yapılırken yoğunluk fonksiyonel teorisi metodu kullanıldı). Hesaplanan infrared ve nükleer manyetik rezonan değerlerinin deneysel değerler ile uyumlu olduğu görüldü. Bileşiğin moleküler geometrisi, geometrik yapısı ve geometrik parametreler gibi kuantum kimyasal hesaplamarı 6-311G(d,p) temel seti ile hesaplandı. HOMO-LUMO arasındaki enerji farkı, kimyasal sertlik ve kimyasal yumuşaklık gibi elektronik özelliklerin kuantum kimyasal hesaplamarı yapıldı. 4-Kumarinil-4-florobenzoat'`n moleküler elektrostatik potansiyel (MEP) yüzeyi elde edildi.
\end{abstract}

Anahtar kelimeler: DFT, kumarin, HOM-LUMO, moleküler modelleme.

\section{Experimental and quantum chemical calculations of coumarin-structured compound containing Benzoate ester}

\begin{abstract}
The aim of the study was to synthesize 4-Coumarinyl-4-fluorobenzoate and detect its experimental and theoretical properties. 4-Coumarinyl-4-fluorobenzoate was synthesized using by the nucleophilic adduction-separation reaction of aroyl compounds. In this context 4-coumarinyl 4-fluorobenzoate compound has been characterized both experimentally and theoretically by using quantum chemical calculations and spectral techniques. Nuclear magnetic resonances and infrared spectroscopic values of ${ }^{1} \mathrm{H}$ and ${ }^{13} \mathrm{C}$ in the basic state of the title compound were calculated both experimentally and theoretically (Density functional theory method was used while making theoretical calculations). It was seen that the calculated infrared and nuclear magnetic resonance values were compatible with the experimental values. Quantum chemical calculations such as the molecular geometry, geometric structure, and geometric parameters of the title compound were calculated with the 6-311G (d, p) basis set. Quantum chemical calculations of electronic properties such as energy difference between HOMO-LUMO, chemical hardness and chemical softness were made. Molecular electrostatic potential (MEP) surface of 4Coumarinyl-4-fluorobenzoate was obtained.
\end{abstract}

Keywords: DFT, coumarin, HOMO-LUMO, molecular modeling.

\section{Giriş}

Kumarinler bitkilerden özellikle de yeşil bitkilerden izole edilen ve oksijen içeren heterosiklik bileşiklerdir. Doğal olarak elde edilen yaklaşık 1300 kadar kumarin türevi bilinmektedir. Tonka fasülyesi, akasya, lavanta, kayısı, çilek ve tarçını kapsayan pek çok bitkinin meyve, kabuk, gövde ve

\footnotetext{
*Sorumlu yazar: ksarac@beu.edu.tr

Geliş Tarihi: 03.11.2020, Kabul Tarihi: 27.11.2020
} 
yapraklarında doğal olarak bulunur. Bitkilerden izole edilen doğal kumarinlerin yanında sentetik kumarin türevleri de mevcuttur. Kumarin ve türevleri farklı hastalıkların tedavisinde kullanılıp antikoagulant, antialerjik, antibiyotik, diüretik, anti-HIV, antibakteriyel gibi birçok biyolojik özellikler gösterir. Biskumarinlerden olan dikumaril ve türevlerinin antikoagulant etkisi gösterdiği ve bu bileşikler kanın pıhtılaşmasında azaltıcı etkisinin olduğu ve tedavi edici ilaçların yapımında kullanıldığı bilimektedir. 4-Hidroksikumarin yapısında olan warfarin bilinen en iyi antikoagulanttır. Novabiosin ve Klorobiosin antibiyotik ve antibakteriyel özellik gösteren kumarin türevi olup kötü farmo kinetik ve toksik önleyici özelliğe sahiptir [1]. Farmokolojik özelliklerinden dolayı benzokumarin ve benzokromonlar son zamanlarda üzerinde çalışılan bileşiklerdir. Bu bileşikler ayrıca tekstil sanayiinde sentetik elyafın parlaklığını arttırıcı olarak kullanılmaktadır [2]. Kumarin türevlerinin fotofiziksel özellikleri yapıda bağlı bulunan gruplara ve çözücü ortamına göre farlılık göstermektedir. Kumarin türevleri, önemli lazer boyarmaddeleri, non-lineer optik kromofor ve homojen çözeltilerdeki çözünürlük dinamiği çalışmaları için mükemmel bir yanıt verme özelliğine sahip olduklarından geniş bir çalışma alanı bulmaktadır [3]. Kumarin boyalarının önemli bir kısmı organik ışık yayıcı diyotlarda (OLEDs) mavi, yeşil ve kırmızı katkı maddesi olarak kullanılmaktadır. Ancak, kumarinboyaları moleküller arası etkileşimlerden dolayı yüksek derişimlerde kolaylıkla kendi kendine sönümleme yapmaktadır. $\mathrm{Bu}$ yüzden 1şık yayıcı materyallerde luminesant verimliliğe sahip OLED'ler imal etmek için her zaman uygun konsantrasyonlarda kullanılmas1 gerekir [4].

Kumarin türevlerinin bu kadar geniş ve çeşitli alanlarda kullanılmasından dolayı bu alanların en az birinde kullanılması amacı ile ilk defa bu çalışmada 4-Hidroksikumarin ve 4-florobenzoil klorür aroil bileşiklerin nükleofilik katılma ayrılma tepkimesi üzerinden gerçekleştirilmesi ile, oluşan 4-Kumarinil4-florobenzoat'ın hem deneysel hem de kuantum kimyasal hesaplanması hedeflenmiştir.

\section{Materyal ve Metot}

\subsection{Deneysel Kısım}

\section{4-Kumarinil 4-florobenzoat Sentezi (III)}

$100 \mathrm{~mL}$ ' lik bir behere 4-hidroksikumarin (1,62 g, $10 \mathrm{mmol})$ ve piridin $(2 \mathrm{~mL}, 25 \mathrm{mmol})$ konulup hafifçe karıştırılarak 4-hidroksikumarin'in çözünmesi sağlandı. Bu çözeltiye 4-florobenzoil klorür (10 mmol ) damla damla ilave edilerek 30-40 dakika arasında karıştırıldı. Oluşan karışım seyreltik hidroklorik asit içeren buzlu su içine ilave edildi. Katının çökmesi gözlendi. Madde bol su ile yıkanıp süzüldükten sonra \%5 lik sodyum bikarbonat içeren $100 \mathrm{~mL}$ çözeltiye konup iyice karıştırıldı. Ürün su ile yıkandıktan sonra tekrar süzülüp kurumaya bırakıldı. Kurutulan madde etanolde kristallendirildi. Elde edilen ürünün yapısı spektral tekniklerle aydınlatıldı. Ürünün genel elde reaksiyonu Şekil 1'de verilmiştir. $\mathrm{C}_{16} \mathrm{H}_{9} \mathrm{FO}_{4}$ (M.A $=284.24 \mathrm{~g} / \mathrm{mol}$, verim $=\% 56)$<smiles>O=c1cc(O)c2ccccc2o1</smiles>

(I)<smiles>O=C(Cl)c1ccc(F)cc1</smiles>

(II)<smiles>O=C(Oc1cc(=O)oc2ccccc12)c1ccc(F)cc1</smiles>

(III)

Şekil 1. 4-Kumarinil 4-florobenzoat'1n sentezi [5].

\subsection{Teorik Kısım}

Bütün teorik hesaplamalar Gaussian 09W[6] ve GausView 5.0[7] paket programı kullanılarak, yapılmıştır. Sonuçlar GausView ile görüntülenerek değerlendirilmiştir. Hesaplamalar yapılırken 6$311 \mathrm{G}(\mathrm{d}, \mathrm{p})$ temel seti kullanılarak enerji değerleri ve geometrik parametreler elde edildi. Hesaplamalarda Moleküllere ait geometri optimizasyonları, Mulliken yükleri, dipol momentler, IR spektrumu, 
moleküllere ait minimum enerjili şekillerinin araştırması, moleküler elektrostatik potansiyel yüzeyleri, sınır orbitalleri ise yoğunluk fonksiyonel teorisi yöntemi kullanılarak elde edilmiştir. Teorik yöntemlerden elde edilen IR titreşim frekansları sonuçlarını deneysel sonuçlara yakınlaştırmak için literatürlerde yer alan düzeltme çarpanı değerleri ile çarpılması gerekmektedir. Bu düzeltme çarpanı değeri B3LYP/6-311G(d,p) için 0,9813 olarak alınmıştır [8]. Sentezlenen 4-Kumarinil 4florobenzoat'ın optimize edilmiş hali Şekil 2'de verilmektedir.

a)<smiles>Cc1ccc(C(=O)Oc2cc(=O)oc3ccccc23)cc1</smiles>

b)

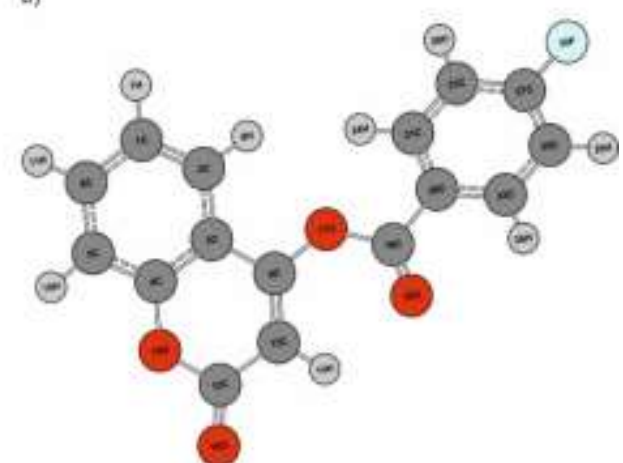

Şekil 2. (a) 4-Kumarinil 4-florobenzoat'in deneysel şekli (b) 4-Kumarinil 4-florobenzoat'in teorik şekli.

\section{Bulgular ve Tartışma}

\subsection{Sentezlenen C16H9FO4 Molekülünün Analizi}

4-hidroksikumarin, 4-florobenzoil klorür ile aroil bileşiklerin nükleofilik katılma ayrılma tepkimesi üzerinden gerçekleştirilmiş olup, iyi bir verimle (\%76) 4-Kumarinil 4-florobenzoatı oluşturur. Bileşiğin reaksiyon oluşum mekanizması şekil 3'te verilmiştir. Şekil 3'te görüldügü gibi oksijen üzerinde bulunan ortaklanmamış elektron çiftleri kısmı pozitif halde bulunan açil yapıdaki karbonil karbonuna nükleofilik katılma gerçekleştirir daha sonra klor atomu elektronegatifliği yüksek olduğundan elektronları alarak yapıdan bir mol hidroklorik asit $(-\mathrm{HCl})$ ayrılmasıyla reaksiyon tamamlanmış olur.

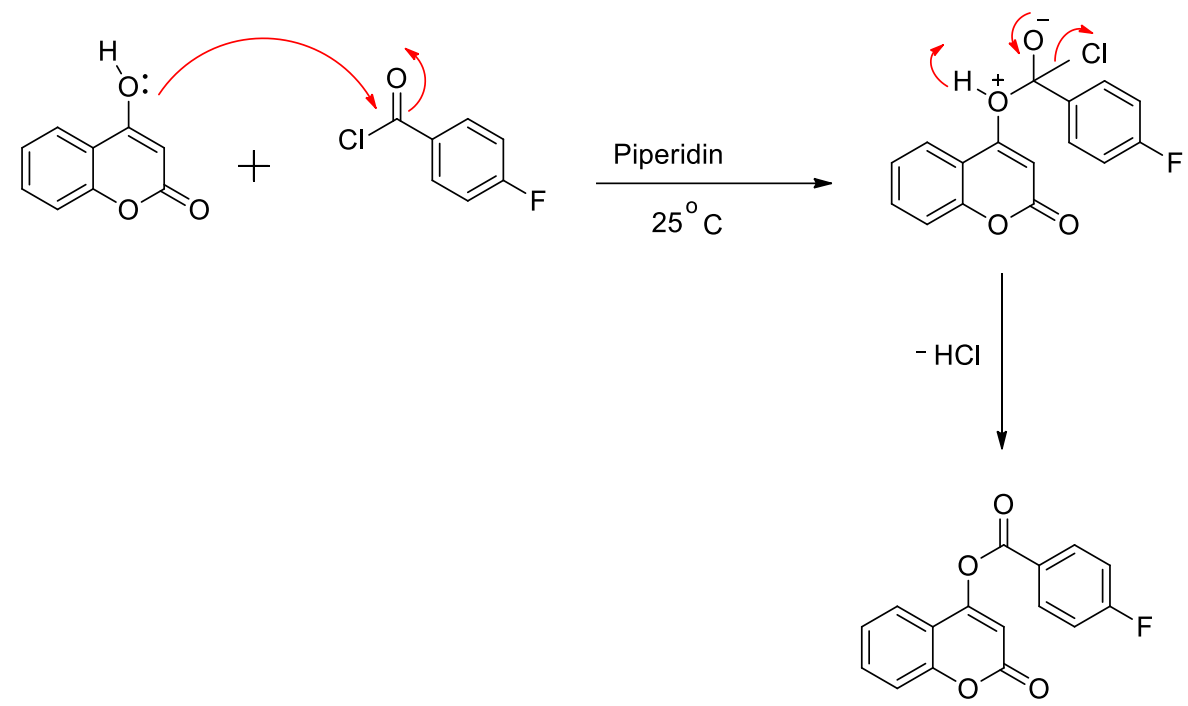

Şekil 3. 4-Kumarinil 4-florobenzoat'nn oluşum mekanizması

\section{2. İnfrared Spektroskopisi (IR)}

4-Kumarinil 4-florobenzoat'ın titreşim frekanslarının teorik olarak hesaplanan infrared spektrum sonuçları deneysel değerlerle karşılaştırıldı. Bileşikte $\mathrm{CO}, \mathrm{CH}$ ve $\mathrm{CC}$ gerilme (simetrik ve antisimetrik), düzlem içi ve düzlem dışı $\mathrm{CH}$ eğilme, aromatik $\mathrm{CH}$ ve $\mathrm{CC}$ gerilme titreşimleri bulunmaktadır. Aromatik $\mathrm{CH}$ gerilme titreşimleri 300-3100 cm${ }^{-1}$, de çoklu bandlar şeklinde görülmektedir. Düzlem içi CH eğilme 
titreşimleri 1100-1500 $\mathrm{cm}^{-1}$ bölgesinde keskin pikler şeklinde görülmektedir. Düzlem dışı eğilme titreşimleri ise $800-1000 \mathrm{~cm}^{-1}$ bölgesinde görülmektedir $[9,10]$. Bileşiğin aromatik halkada teorik olarak hesaplanan CH gerilme titreşimleri 2979-3087 $\mathrm{cm}^{-1}$ aralığında görülürken deneysel olarak 2990-3060 $\mathrm{cm}^{-1}$ aralığında gözükmektedir. Düzlem içi eğilme titreşimleri teorik olarak $1368-1483 \mathrm{~cm}^{-1}$ de deneysel olarak 1350-1415 $\mathrm{cm}^{-1}$ aralığında, düzlem dışı eğilme titreşimleri teorik olarak 929-1176 $\mathrm{cm}^{-1} \mathrm{de}$, deneysel olarak $885-1130 \mathrm{~cm}^{-1}$ aralıklarında gözükmektedir. 4-Hidroksikumarin yapısında 3200-3600 $\mathrm{cm}^{-1}$ aralığında $\mathrm{OH}$ gerilimine ait pik bulunurken [11]. Reaksiyon sonucunda oluşan C16H9FO4 molekülünde bu pik kaybolmakta ve bunun yerine ester oluşumunu gösteren $\mathrm{C}=\mathrm{O}$ piki gözükmektedir. Ester yapısını gösteren $\mathrm{C}=\mathrm{O}$ gerilme titreşimleri $1710-1770 \mathrm{~cm}^{-1}$ frekans aralığında(keskin pik şeklinde), C-O gerilme titreşimleri 1300-1100 $\mathrm{cm}^{-1}$ frekans aralığında (orta şiddette), görülmektedir [12]. Bileşiğin ester yapısını gösteren $\mathrm{C}=\mathrm{O}$ gerilme titreşimi teorik olarak $1759 \mathrm{~cm}^{-1}$, deneysel olarak $1740 \mathrm{~cm}^{-1} \mathrm{de}$ gözükmektedir, Öte taraftan C-O gerilme titreşimi teorik olarak $1124 \mathrm{~cm}^{-1}$, deneysel olarak $1100 \mathrm{~cm}^{-1}$ de gözükmektedir. Teorik ve deneysel değerler arasında bazı farklılıklar görülmektedir. Bunun en büyük sebepleri arasında 1: Teorik sonuçların gaz fazında, deneysellerin ise katı fazda alınmasından 2: Gaussian infrared hesaplamaların harmonik frekanslara ait olması ancak gerçekte moleküllerde anharmonik salınımların olmasıdır. Fakat genel olarak teorik ve deneysel değerlerin iyi bir uyum içinde olduğu söylenebilir. Bileşiğin (C16H9FO4) diğer titreşim değerleri Tablo 1'de ayrıca deneysel ve hesaplanan ve infrared spektrumları da Şekil 4 'te verilmektedir.

Tablo 1. 4-Kumarinil-4-florobenzoat titreşim frekanslarının karşılaştırılması

\begin{tabular}{llll}
\hline Semboller & Hesaplanan & Deneysel \\
& & B3LYP/6-311G(d,P) & FT-IR(cm $\left.\mathbf{c m}^{-\mathbf{1}}\right)$ \\
\hline vs & $\mathrm{C} 13-\mathrm{H}$ & 3087 & 3060 \\
vs & $\mathrm{C} 23-\mathrm{H}+\mathrm{C} 21-\mathrm{H}$ & 3038 & - \\
os & $\mathrm{C} 25-\mathrm{H}+\mathrm{C} 22-\mathrm{H}$ & 3032 & - \\
v & $\mathrm{C} 2-\mathrm{H}+\mathrm{C} 1-\mathrm{H}+\mathrm{C} 6-\mathrm{H}+\mathrm{C} 5-\mathrm{H}$ & 3029 & 3015 \\
vas & $\mathrm{C} 5-\mathrm{H}+\mathrm{C} 4-\mathrm{H}+\mathrm{C} 2-\mathrm{H}$ & 3024,3010 & - \\
vas & $\mathrm{C} 23-\mathrm{H}+\mathrm{C} 25-\mathrm{H}$ & 3022,3018 & - \\
vas & $\mathrm{C} 6-\mathrm{H}+\mathrm{C} 5-\mathrm{H}$ & 2979 & 2990 \\
$v$ & $\mathrm{C} 12=\mathrm{O} 16$ & 1774 & 1770 \\
$v$ & $\mathrm{C} 18=\mathrm{O} 19$ & 1759 & 1740 \\
$v$ & $\mathrm{C} 3=\mathrm{C} 9$ & 1560 & - \\
$\delta$ & $\mathrm{C} 25-\mathrm{H}+\mathrm{C} 22-\mathrm{H}$ & 1483, & - \\
$\delta$ & $\mathrm{C} 6-\mathrm{H}+\mathrm{C} 1-\mathrm{H}+\mathrm{C} 5-\mathrm{H}$ & 1461,1425 & 1415 \\
$\delta$ & $\mathrm{C} 25-\mathrm{H}+\mathrm{vs} \mathrm{C} 21=\mathrm{C} 23$ & 1368 & 1350 \\
$v$ & $\mathrm{C} 6=\mathrm{C} 5+\mathrm{C} 3=\mathrm{C} 4$ & 1321 & - \\
$v$ & $\mathrm{C} 21=\mathrm{C} 23+\mathrm{C} 22=\mathrm{C} 25$ & 1312 & - \\
$\alpha$ & $\mathrm{C} 13-\mathrm{H}+\mathrm{C} 9-\mathrm{O} 17$ & 1176 & 1130 \\
$\alpha$ & $\mathrm{C} 6-\mathrm{H}+\mathrm{C} 5-\mathrm{H}$ & 1138 & 1033 \\
$v$ & $\mathrm{C} 18-\mathrm{O} 17$ & 1124 & 1100 \\
$\alpha$ & $\mathrm{C} 27-\mathrm{H}+\mathrm{C} 25-\mathrm{H}$ & 929 & 885 \\
\hline
\end{tabular}

$v$, gerilme; $\delta$, düzlem içi eğilme; $\alpha$, düzlem dışı eğilme; s, simetrik; as, asimetrik;

a)

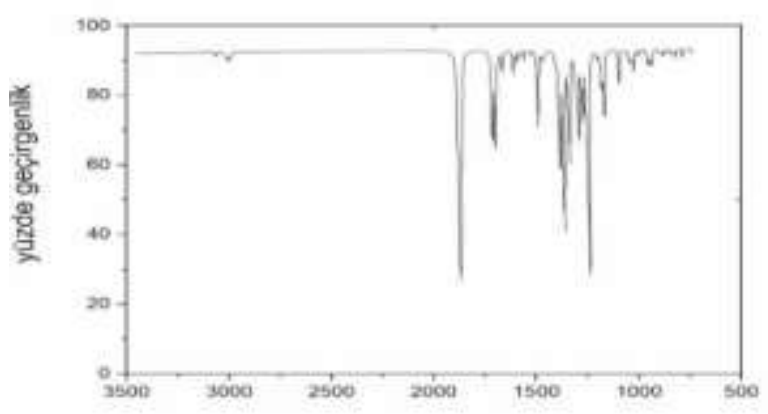

b)

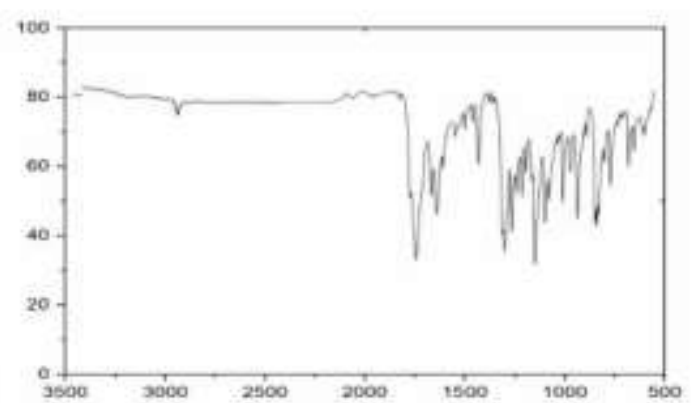

daldasayısı(cm-1)

Şekil 4. a) Bileşiğin teorik olarak hesaplanan infrared spektrumu, (b) Deneysel İnfrared spektrumu 


\subsection{Nükleer Manyetik Rezonans Spektroskopisi (NMR)}

Sentezlenen C16H9FO4 molekülünün ${ }^{1} \mathrm{H}$ - ve ${ }^{13} \mathrm{C}-\mathrm{NMR}$ deneysel kimyasal kayma değerleri belirlenmiş ve teorik hesaplama sonucu elde edilen değerlerle karşılaştırılmıştır. ${ }^{13} \mathrm{C}-\mathrm{NMR}$ kimyasal kayma değerleri incelendiğinde benzoil halkasındaki karbon atomlarının kimyasal kayma değerleri deneysel olarak 107.5-167.5 ppm aralığında teorik olarak 115.4-168.1 ppm aralı̆̆ında gözlenmiştir ancak bu halkadaki C27 nolu karbon atomunun diğer karbon atomlarına göre daha düşük alanda deneysel olarak 167.5 ppm'de teorik olarak 168.1 ppm'de çıktığ 1 görüşmüştür. Bunun nedeni ise bu karbon atomuna bağlı bulunan flor atomundan kaynaklanmaktadır. Flor atomu elektronegatifliği yüksek bir atomdur buda komşu karbon atomu olan C27 nolu karbonun etrafındaki elektron yoğunluğunu azaltıp daha düşük alanda rezonansa girmesine sebep olmuştur. Diğer yandan kumarin halkasında bulunan karbon atomlarının kimyasal kayma değerleri deneysel olarak 78.2 -169 ppm aralığında teorik olarak 99.7-174.4 ppm aralığında gözlenmiştir. Bu karbon atomlarından C9 nolu karbon atomununda çok yüksek ppm'de (deneysel olarak 169 ppm' de teorik olarak 174.4 ppm'de) çıktığ görülmüştür. Bunun sebebi ise bu karbon atomunun oksijen atomuna bağlı olmasıdır. Oksijen indüktif olarak elektron çeken atomdur [13]. $\mathrm{Bu}$ etki karbon atomun çevresindeki elektron yoğunluğunu azaltır, bu da karbon atomunun kimyasal kayma değerlerinin daha yüksek ppm'de görülmesine neden olmaktadır. ${ }^{1} \mathrm{H}-\mathrm{NMR}$ kimyasal kayma değerleri incelendiğinde ise en karakteristik proton 13 nolu karbon atomuna bağlı bulanan protondur kumarin halkasının varlığını gösteren bu proton deneysel olarak 6.60 ppm'de teorik olarak 6.24 ppm'de çıkmıştır. Kumarin ve benzoil halkasının diğer protonları deneysel olarak 7.10-8.50 ppm aralığında teorik olarak 7.42-819 ppm aralığında gözükmektedir. Ayrıca bileşiğin deneysel olarak ${ }^{1} \mathrm{H}-\mathrm{ve}{ }^{13} \mathrm{C}$ NMR'ları Şekil 5'te, deneysel ve teorik olarak hesaplanan ${ }^{1} \mathrm{H}$ - ve ${ }^{13} \mathrm{C}-\mathrm{NMR}$ spektrum değerleri Tablo 2 'de verilmektedir.
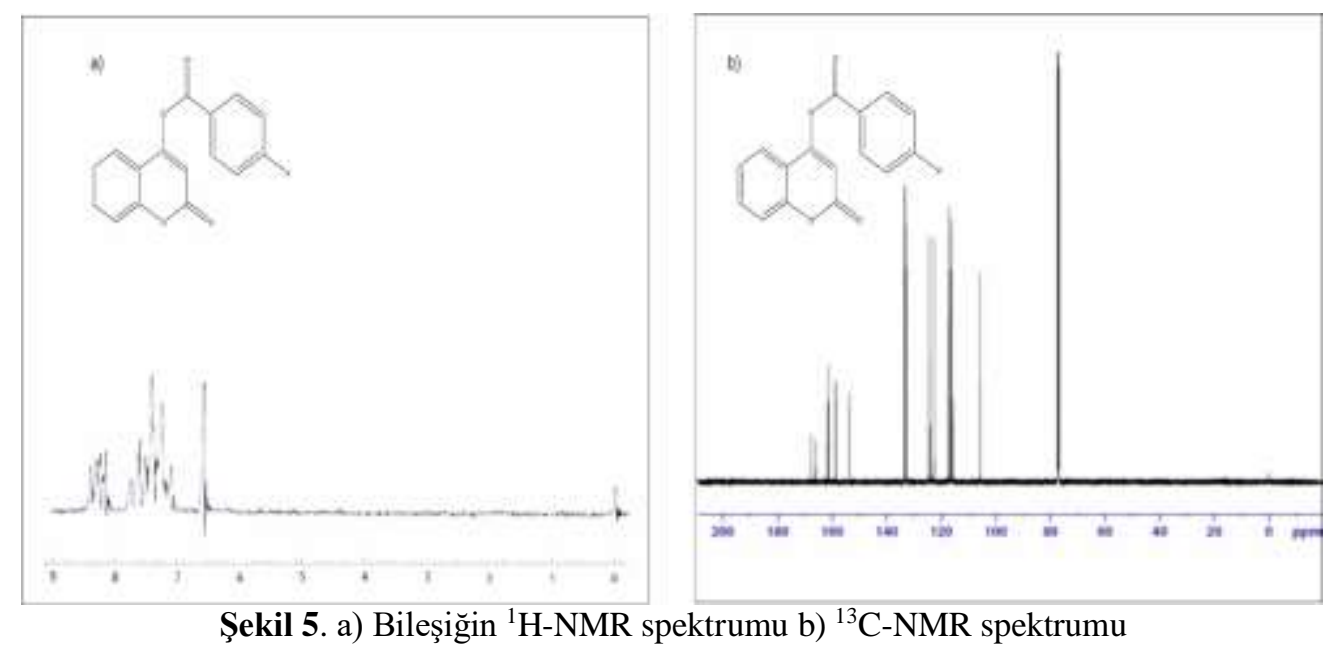

Tablo 2. Bileşiğin deneysel ve hesaplanan NMR spektrum değerleri

\begin{tabular}{lcc}
\hline Atom & Deneysel(ppm) DMSO-d $_{\mathbf{6}}$ & Hesaplanan(ppm) B3LYP/6-311G(d,p) \\
\hline C1 & 124.1 & 125.4 \\
C2 & 123.8 & 123.3 \\
C3 & 117.9 & 117.4 \\
C4 & 154.0 & 152.5 \\
C5 & 118.2 & 116.4 \\
C6 & 125.6 & 128.3 \\
C9 & 169.0 & 174.2 \\
C12 & 162.3 & 162.4 \\
C13 & 78.2 & 99.7 \\
C18 & 154.0 & 153.6 \\
C20 & 123.8 & 123.8 \\
C21 & 133.1 & 131.9 \\
C22 & 133.1 & 131.9 \\
C23 & 107.5 & 115.4 \\
C25 & 107.5 & 115.9 \\
C27 & 167.5 & 168.1 \\
H(C13) & 6.60 & 6.24 \\
8H(kumarin ve benzoil) & $7.10-8.50$ & $7.42-8.19$ \\
\hline
\end{tabular}




\subsection{Frontier Moleküler Orbitaller (FMOs) ve Elektronik Özellikler}

Frontier moleküler orbital teorisi, HOMO-LUMO etkileşimlerini tanımlayan moleküler orbital teorisinin bir uygulamasıdır. Bu teoriye göre; Molekülün elektron verme yeteneği HOMO enerjisi, molekülün elektron alma yeteneği LUMO enerjisi olarak tanımlanır. HOMO ve LUMO orbitalleri tepkimelerde kritik öneme sahip oldukları için bunlara öncü orbitaller de denilebilir [14]. Şekil 6'da görüldüğ̈̈ gibi, HOMO-1 ve HOMO elektronları kumarin halkasında delokalize olduğu, LUMO ve LUMO+1 elektronları kumarin ve benzoat halkasındadelokalize olduğu görülmektedir. $\Delta \mathrm{E}$ değeri molekülün kimyasal kararlılığı ile yakından ilgilidir. $\Delta \mathrm{E}$ enerji farkı ne kadar düşükse reaksiyona giren yapıların etkileşimi ve tepkime o kadar kolay olacaktır. 4-Kumarinil-4-florobenzoatı bileşiğinin $\Delta \mathrm{E}$ ( $\mathrm{E}_{\text {номо- }} \mathrm{E}_{\mathrm{LUMO}}$ ) farkını bulmak için B3LYP/6-311G(d,p) seviyesinde hesaplamalar yapılmıştır. 4Kumarinil-4-florobenzoat bileşiğinin elde edilen $\Delta \mathrm{E}$ değeri $4.378 \mathrm{eV}$ olduğu görülmektedir ve bu değere göre molekülün oldukça kararlı bir yapıya sahip olduğu söylenebilir. Yalnızca HOMO ve LUMO'nun dikkate alınması, sınır yörüngelerinin gerçekçi bir tanımını vermeyebilir, çünkü sınır bölgesinde, komşu yörüngeler yarı dejenere enerji seviyeleri gösterebilir. Bu nedenle durumların yoğunluğu (DOS), Gauss Sum 3.0 yazılımı kullanılarak hesaplanmıştır [15].

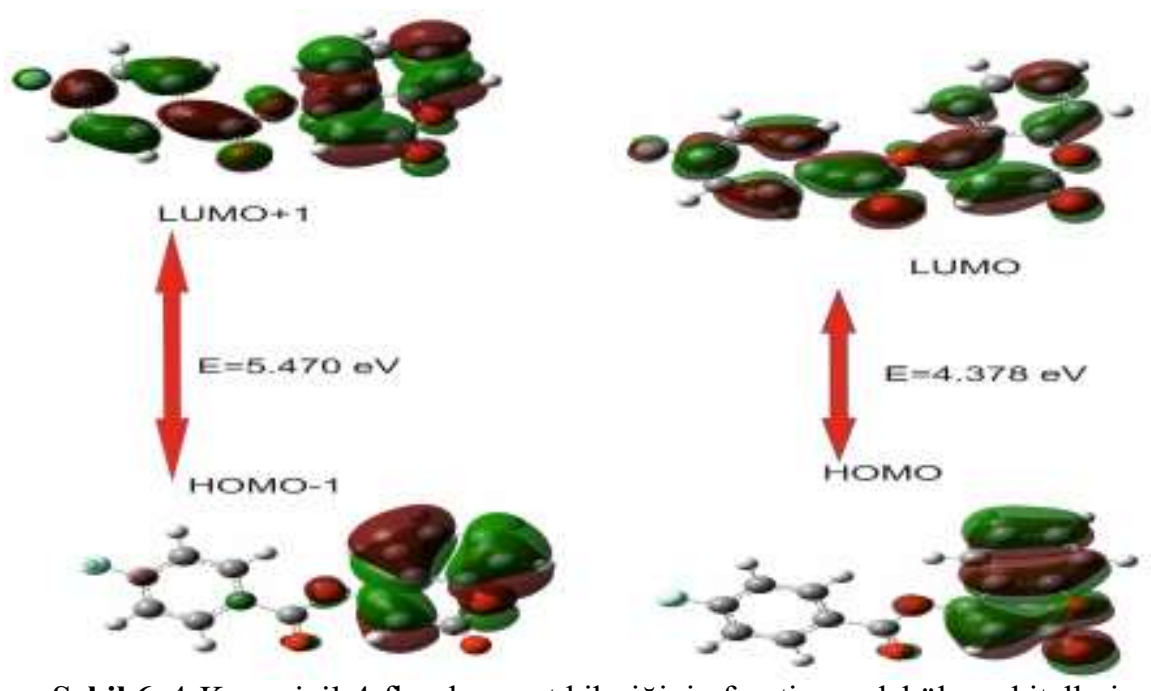

Şekil 6. 4-Kumarinil-4-florobenzoat bileşiğinin frontier moleküler orbitalleri

Şekil 7'den de görüldüğü üzere sınır bölgelerinde dejenere bir durum olmadığı söylenebilir. 4Kumarinil-4-florobenzoat bileşiğinin HOMO ve LUMO orbital enerji değerleri bilinirse; Elektron ilgisi, Elektronegatiflik, Kimyasal sertlik, Kimyasal yumuşaklık gibi parametreler bulunabilir[16]. Teorik olarak hesaplanan bileşiğin elektronik yapı parametre değerleri Tablo 3'te verilmiştir.

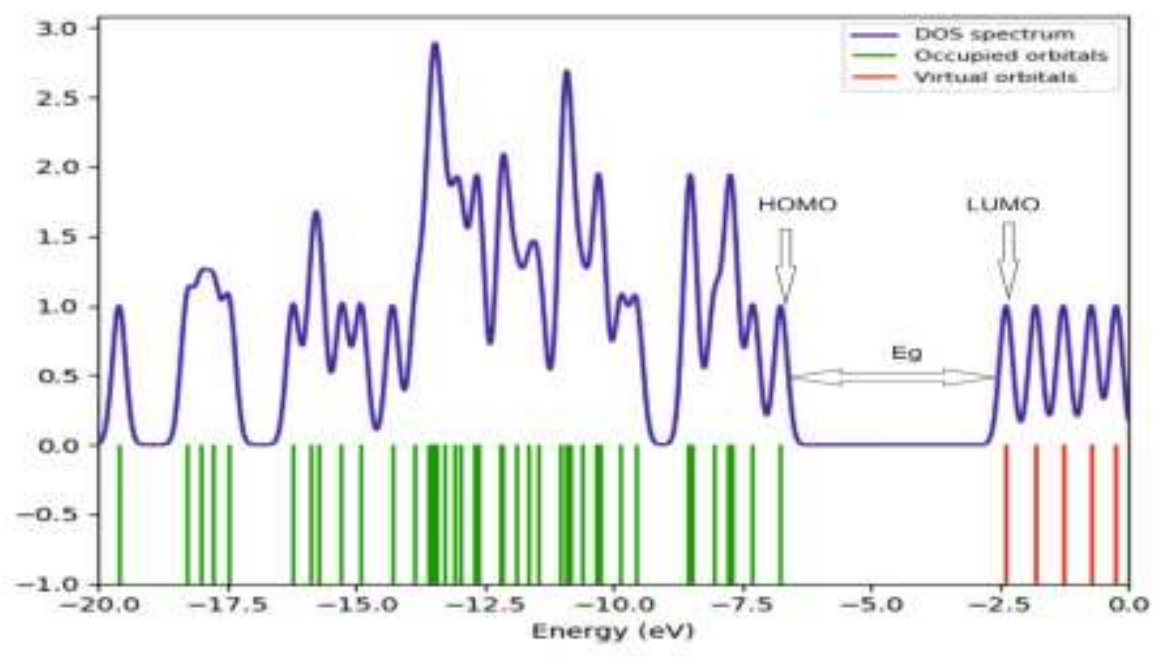

Şekil 7. Bileşiğin DOS diagramı 
Tablo 3. 4-Kumarinil-4-florobenzoat bileşiğinin elektronik yapı parametreleri

\begin{tabular}{lc}
\hline & B3LYP/6-311G(d,p) \\
\hline $\mathrm{E}_{\text {Hомо }}(\mathrm{eV})$ & -6.748 \\
$\mathrm{E}_{\text {LUMO }}(\mathrm{eV})$ & -2.370 \\
$\Delta \mathrm{E}(\mathrm{eV})$ & 4.378 \\
$\mathrm{I}(\mathrm{eV})$ & 6.748 \\
$\mathrm{~A}(\mathrm{eV})$ & 2.370 \\
$\mathrm{X}(\mathrm{eV})$ & 4.559 \\
$\eta(\mathrm{eV})$ & 2.189 \\
$\mathrm{~S}\left(\mathrm{eV}^{-1}\right)$ & 0.456 \\
\hline
\end{tabular}

\subsection{Moleküler Elektrostatik Potansiyel (MEP)}

Moleküler elektrostatik potansiyel (MEP) yüzeyinin üç boyutlu şekilleri moleküler elektrostatik potansiyel haritaları olarak da bilinir. MEP haritasında ortaya çıkan yüzey, moleküler büyüklük, şekil, yük dağılımı ve elektrostatik potansiyel değerini göstermektedir. Yük dağılımı bilgisi yüke bağlı özellikleri ve moleküllerin birbirleriyle etkileşimini belirlemek için kullanılır. Moleküler elektrostatik potansiyel (MEP) haritasında, kırmızı bölge: molekülün dıştaki elektronları kuvvetle iten elektronca zengin bir bölge ve en düşük potansiyel enerjiye sahiptir. Ayrıca elektronegatif potansiyellere sahip bölgeyi gösterir. Moleküler elektrostatik potansiyel (MEP) haritasında, kırmızı bölge: Molekülün dıştaki elektronları çok kuvvetle çeken elektronca fakir bir bölge ve pozitif yüklü olup en yüksek potansiyel enerji değerine sahiptir [17,18]. 4-Kumarinil-4-florobenzoat bileşiğine ait moleküler elektrostatik potansiyel haritası Şekil 8'de verilmiştir. Bileşiğin negatif bölgesi kumarin halkasındaki oksijen ve karbonil gurubu etrafına yoğunlaşırken pozitif bölgenin ise kısmı olarak benzoil üzerine yerleştiği görülmektedir.

a)

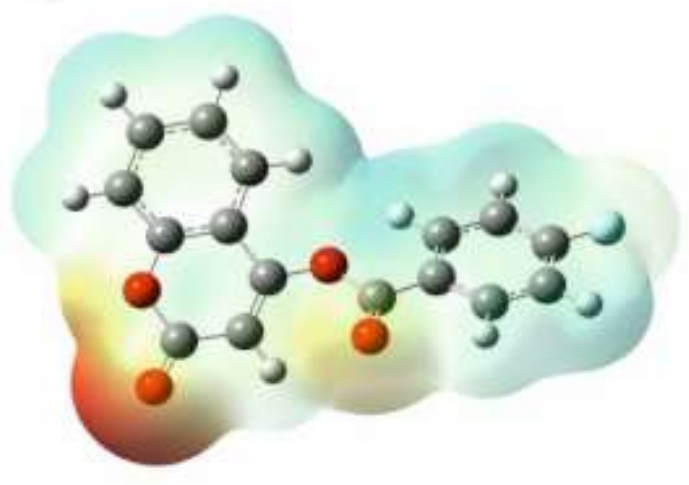

b)

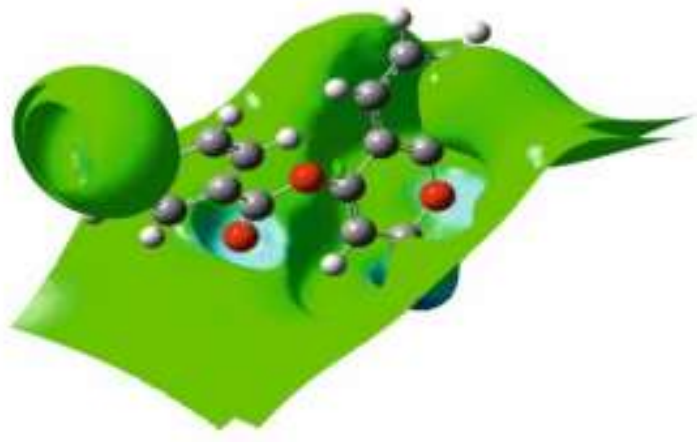

c)

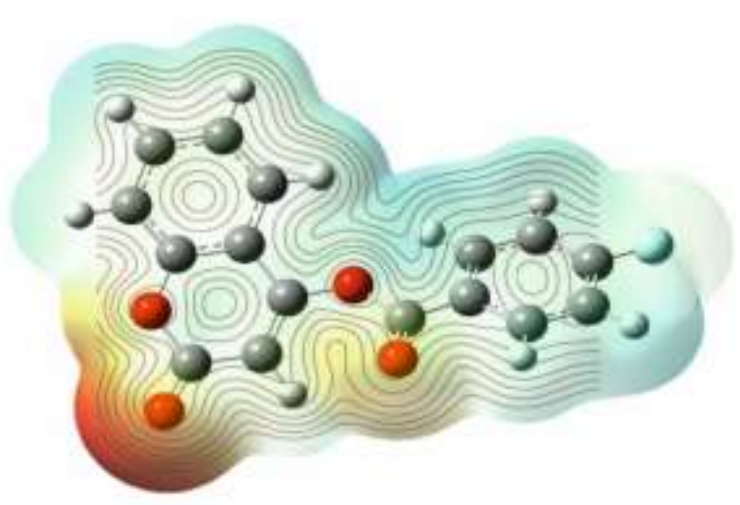

Şekil 8. a) Bileşiğin B3LYP/6-311G(d,p) seviyesinde hesaplanan Moleküler Elektrostatik Potansiyel haritası. b) Bileşiğin ESP şekli ) (c) Bileşiğin Contour shape şekli. 


\section{Sonuç ve Öneriler}

Sonuç olarak, 4-Kumarinil-4-florobenzoat bileşiğinin molekül yapıları, spektroskopik özellikleri ve elektron özellikleri deneysel ve kuantum mekaniksel yöntemler kullanılarak araştırılmış ve bu molekülerin yapısal ve spektroskopik karakterizasyonu hakkında detaylı bilgiler verilmiştir. Sunulan bu bigilerin ışığı altında bu yapının kullanın alanlarının çeşitliliğinin artması amaçlanmıştır.

\section{Yazarların Katkısı}

Kamuran SARAÇ bu çalışmada deneyleri ve teorik çalışmaları yaparak veri değerlendirmesinde katkı sağlamıştır. Serap ÇETINKAYA deneysellerin yapımında ve verilerin değerlendirilmesinde katkı sağlamıştır.

\section{Çıkar Çatışması Beyanı}

Yazarlar arasında herhangi bir çıkar çatışması bulunmamaktadır.

\section{Araştırma ve Yayın Etiği Beyanı}

Yapılan çalışmada araştırma ve yayın etiğine uyulmuştur.

\section{Kaynaklar}

[1] Bouasla S., Amaro-Gahete J., Esquivel D., López M.I., Jiménez-Sanchidrián C., Teguiche M., Romero-Salguero F. 2017. Coumarin derivatives solvent-free synthesis under microwave irradiation over heterogeneous solid catalysts. Molecules, 22 (12): 2072-2080.

[2] Kolanc1lar H. 2019. DFT Yöntemi Kullanılarak 1, 3-Bis-\{(2-Aminobenzoil) Amino\} Propanın Teorik Hesaplamaları ve Bu Değerlerin Literatürdeki Deneysel Değerler ile Karşılaştırılması. Düzce Üniversitesi Bilim ve Teknoloji Dergisi, 7 (3): 1319-1334.

[3] Abdel M.S.A., Hamed E., Saif M., Hafez S. 2018. Binding, and thermodynamics of $\beta$ cyclodextrin inclusion complexes with some coumarin laser dyes and coumarin-based enzyme substrates: a simulation study. Journal of Inclusion Phenomena and Macrocyclic Chemistry, 92 (3): 319-327.

[4] Yu T., Zhu Z., Bao Y., Zhao Y., Liu X., Zhang, H. 2017. Investigation of novel carbazolefunctionalized coumarin derivatives as organic luminescent materials. Dyes and Pigments, 147 (1): 260-269.

[5] Babinski D., Soltani O., Frantz D.E. 2008. Stereoselective synthesis of acetoacetate-derived enol triflates. Organic Letters, 10 (13): 2901-2904.

[6] Frisch M.J.E.A., Trucks G.W., Schlegel H.B., Scuseria G.E., Robb M.A., Cheeseman J.R., Nakatsuji H. 2009. gaussian 09, Revision d. 01, Gaussian. Inc., Wallingford CT, 201.

[7] Becke A.D. 1993. Density-Functional Exchange-Energy Approximation With Correctasymptotic Behavior. Phys Rev A Gen Phys. 98: 3098-3100.

[8] Becke A.D. 1993. A new Mixing of Hartree-Fock and Local Density-Functional Theories. Chem. Phys., 98: 372-1377.

[9] Govindarajan S., Nagabalasubramanian P.B. 2015. Molecular structure and spectroscopic properties of 4-methoxybenzaldehyde based on density functional theory calculations. J. Adv. Sci. Eng. 2 (2): 75-86

[10] Du XH, Hansell C, Doyle E.P, Caffrey C.R, Holler T.P, McKerrow J.H, Cohen F.E.2002. Synthesis and Biochemical Evaluation of Thiochromanone Thiosemicarbazone Analogues as Inhibitors of Cathepsin L. J. Med Chem, 45 (13): 2695-2707.

[11] El Oudiani A., Msahli S., Sakli F. 2017. In-depth study of agave fiber structure using Fourier transform infrared spectroscopy. Carbohydrate polymers, 5 (164): 242-248.

[12] Edington A., Sean C., Jennifer C., Carlos R. 2016. An Empirical IR Frequency Map for Ester C= O Stretching Vibrations. The Journal of Physical Chemistry, A 120 (22) : 3888-3896. 
[13] Balcı M. 2008. Organik Kimya Reaksiyon Mekanizmaları. Türkiye Bilimler Akademisi Ders Kitaplar1, Ankara, 1-125.

[14] Hussain J., Angira D., Hans T., Dubey P., Kirubakaran S., Thiruvenkatam V. 2020. Synthesis and characterization of a new class of phenothiazine molecules with $10 \mathrm{H}$-substituted morpholine \& piperidine derivatives: a structural insight. Journal of Molecular Structure, 1219 (5): 12854612858.

[15] O'Boyle N.M., Tenderholt A.L., Langner K.M. 2008. A library for package-independent computational chemistry algorithms. Journal of computational chemistry, 29 (5): 839-845.

[16] Franco P., José L., Gázquez. 2019. Electronegativities of Pauling and Mulliken in Density Functional Theory. The Journal of Physical Chemistry, 123 (46): 10065-10071.

[17] Harrison J.A., Schall J.D., Maskey S., Mikulski P.T., Knippenberg M.T., Morrow B.H. 2018. Review of force fields and intermolecular potentials used in atomistic computational materials research. Applied Physics Reviews, 5 (3): 31104-31114.

[18] Fedorov D.A., Seritan S., Fales B.S., Martínez, T.J., Levine B.G. 2020. PySpawn: Software for Nonadiabatic Quantum Molecular Dynamics. Journal of Chemical Theory and Computation, 16 (9): 5485-5498. 